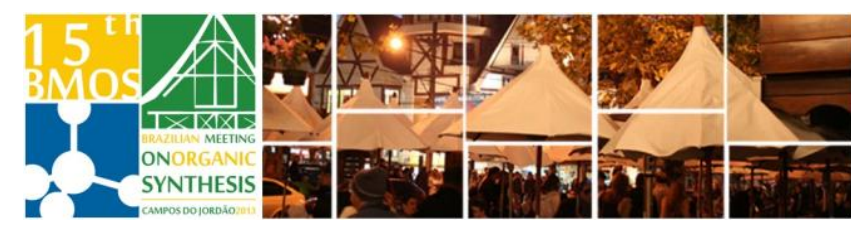

CHELATOR-PEPTIDE CONJUGATE

\title{
AS PROTECTOR AGAINST IRON-INDUCED TOXICITY
}

\author{
D. Goswami ${ }^{1}$, H. A. Vitorino ${ }^{1}$, M. T. Machini ${ }^{2}$, B. P. Esposito ${ }^{1 *}$ \\ Deptos. de ${ }^{1}$ Química Fundamental e de ${ }^{2}$ Bioquímica, Instituto de Química, Universidade de São Paulo. \\ Av. Lineu Prestes 748-05508-000 São Paulo, Brazil \\ *e-mail corresponding author: breno@iq.usp.br
}

Keywords: Penetratin, Desferrioxamine, Iron overload

\section{INTRODUCTION}

Iron, the most abundant metal in human body, accumulates mostly in liver and brain. Iron overload in the brain has also been correlated to the origin of several neurodegenerative disorders, including Parkinson's (PD) and Alzheimer's disease (AD). ${ }^{1}$ Aiming to treat iron overload in the brain, we designed, synthesized and tested a conjugate of Penetratin, a cell-penetrating peptide, with Desferrioxamine, a potent iron chelator.

\section{RESULTS AND DISCUSSION}

Penetratin (RQIKIWFQNRRMKWKK) was synthesized manually by stepwise solid-phase methodology on Wang resin $(0.61 \mathrm{mmol} / \mathrm{g})$ using the Fmoc/tBu strategy. Desferrioxamine was conjugated to the resin-bound peptide by a completely new pathway i.e. chelation of $N$-Succinyldesferrioxamine$\mathrm{B}$ ( $N$-Succinyl group as linker) with iron followed by coupling of $\mathrm{N}$-Succinylferrioxamine-B with the peptidyl-resin. The bound iron was then removed from the conjugate on resin by competitive chelation with Deferiprone. Finally, the $\mathrm{N}$ Succinylferrioxaminyl B-penetratin was cleaved from the resin, fully deprotected, precipitated in dry diisopropyl ether, dissolved in $60 \%$ acetonitrilewater, and freeze-dried. The crude conjugate was purified by RP-HPLC, and characterised by LC/ESIMS and amino acid analysis. To judge the efficacy of this procedure, this method was compared with other little-known procedures to attach Desferrioxamine to a peptide, proving to be superior with respect to final yield and ease of preparation.

Competition studies with calcein and fluorescent transferrin were conducted. These studies established the conjugate as an antioxidant due to immobilization of iron in a stable, redoxinactive form. ${ }^{2}$ However, there was no significant shuttling of iron from ferrioxamine-B to apotransferrin.

Assessment of labile plasma iron (LPI) ${ }^{3}$ was also conducted using ascorbate as oxidant and dihydrorhodamine as probe, both in presence and in absence of the proposed chelator, which in turn entails the specific involvement of labile iron in the process. As shown in Fig. 1, mixtures of $\mathrm{Fe}(\mathrm{III})$ with ascorbate cause a substantial Fe-dependent increase in the of DHR oxidation, whereas the proposed conjugate has a marked inhibitory effect, comparable with that of Deferiprone. The test was repeated with the samples of sera from myelodisplastic patients, some of whom were diagnosed with iron-overload. LPI concentration was determined from calibration curve (obtained by spiking plasmalike medium with $\mathrm{Fe}(\mathrm{NTA})$ at different concentrations) relating the difference in slopes with and without the proposed conjugate against $\mathrm{Fe}$ concentration.
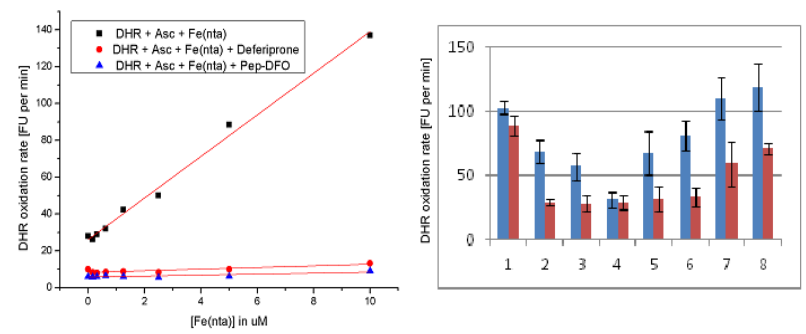

Figure 1. Effects of conjugate on DHR oxidation mediated by iron and ascorbate in (a) plasmalike medium, and (b) on sera of different patients.

\section{CONCLUSION}

Succinylferrioxaminyl B-penetratin is able to decrease sera LPI of iron-overloaded patients. Altogether, our results indicate that this conjugate represents a useful candidate for treating iron overload.

\section{ACKNOWLEDGEMENTS}

Dr. Cleber W. Liria for discussions and technical assistance. DG and HAV are grateful to FAPESP and CAPES for fellowships and financial support.

\section{REFERENCES}

${ }^{1}$ Schroder, N. et. al. J. Alzheimer's Disease 2013, 34, 797-812.

${ }^{2}$ Esposito, B. P.; Epsztejn, S. et. al. Anal. Biochem. 2002, 304, 118.

${ }^{3}$ Esposito, B. P.; Breuer, W. et. al. Blood 2003, 102, 2670-2677.

$15^{\text {th }}$ Brazilian Meeting on Organic Synthesis - $15^{\text {th }}$ BMOS - November 10-13, 2013 - Campos do Jordão, Brazil 